\title{
A Population Health Measurement Framework: Evidence-Based Metrics for Assessing Community-Level Population Health in the Global Budget Context
}

\author{
Elham Hatef, MD, MPH, Elyse C. Lasser, MS, ${ }^{1}$ Hadi H.K. Kharrazi, MD, PhD, ${ }^{1}$ Chad Perman, MPP, \\ Russ Montgomery, PhD, MHS, and Jonathan P. Weiner, $\mathrm{DrPH}^{1}$
}

\begin{abstract}
Population health is one of the pillars of the Triple Aim to improve US health care. The authors developed a framework for population health measurement and a proposed set of measures for further exploration to guide the population health efforts in Maryland. The authors searched peer-reviewed, expert-authored literature and current public health measures. Using a semi-structured analysis, a framework was proposed, which consisted of a conceptual model of several domains and identified population health measures addressing them. Stakeholders were convened to review the framework and identified the most feasible population health measures considering the underlying health information technology (IT) infrastructure in Maryland. The framework was organized based on health system factors, determinants of health, and population-based and clinical outcomes. Measurement specifications were developed that addressed different aspects of selected measures and assessed various national and local data sources for selected measures. Data sources were identified based on their key characteristics, challenges, opportunities, and potential applicability to the proposed measures, as well as the issue of interoperability of data sources among different organizations. The proposed framework and measures can act as a platform to quantify the determinants of health and the state overall population health goals. Key considerations for developing a population health measures framework include health IT infrastructure, data denominators, feasibility, health system environment, and policy factors. Measurement development and progression using the framework will largely depend on the users' focus areas and availability of data. The authors believe that the proposed framework and road map can serve as a model for communities elsewhere.
\end{abstract}

Keywords: population health framework, population health measures, Maryland All-Payer Model, health information exchange

\section{Introduction}

$\mathbf{T}$ HE InSTITUTE FOR Healthcare Improvement (IHI) recommended the simultaneous pursuit of the Triple Aim; namely, improving the experience of care, improving the health of populations, and reducing per capita costs of health care in order to improve the US health care system. ${ }^{1}$ In addition, implementation of interventions oriented to an entire population or subpopulation in a geographic area is one of the 3 "buckets of prevention" recommended by the Centers for Disease Control and Prevention (CDC). ${ }^{2}$

States such as Maryland aim to achieve the Triple Aim and improve the health outcomes as well as health equity for all their residents. In Maryland, improving population health while making sustainable investments in the health care system is a key strategy to health transformation under its Maryland All-Payer Model goals. ${ }^{3}$ Maryland is the nation's first state with an all-payer hospital rate regulation model (known as the All-Payer Model). ${ }^{4}$ A 36-year-old Medicare waiver exempted Maryland from the inpatient and outpatient Prospective Payment Systems and allowed the state to set rates for these services and all third parties to pay the same rate. Under the All-Payer Model, which is made possible in part by the Medicare waiver, Maryland hospitals are committed to achieving significant quality improvements.

\footnotetext{
${ }^{1}$ Center for Population Health IT, Department of Health Policy and Management, Johns Hopkins Bloomberg School of Public Health, Baltimore, Maryland.

${ }^{2}$ Office of Population Health Improvement, Maryland Department of Health, Baltimore, Maryland.

${ }^{3}$ Discern Health, Baltimore, Maryland.
} 
In order to support the goals of the All-Payer Model, Maryland developed the Population Health Improvement Plan. ${ }^{3}$ In addition, it is investing in a number of alternative payment and service delivery models, such as the Maryland Comprehensive Primary Care Model, ${ }^{5}$ and the Medicaid and Medicare Dual Eligibles Care Delivery Strategy. ${ }^{6}$

Maryland also has been preparing for further alignment of its population health initiatives with the progression of the All Payer Model. To align all of the stakeholders in driving toward improvements in community and population health, it is essential to both monitor the health of residents and then to hold the health care delivery system increasingly accountable for indicators deemed appropriate.

Despite the ongoing efforts to transform the delivery of health care and set goals for population health, there is lack of consensus on the specific definition, related indices, and how to measure the status of population health at a state level and its improvement within and across different subpopulations. ${ }^{7,8}$ Over the past few years, major public health organizations, such as the Institute of Medicine (recently renamed as the National Academy of Medicine), ${ }^{9-13} \mathrm{Na}-$ tional Quality Forum (NQF), ${ }^{14-17} \mathrm{IHI},{ }^{18}$ Centers for Medicare \& Medicaid Services (CMS), ${ }^{19-24}$ CDC, ${ }^{25}$ Agency for Healthcare Research and Quality, ${ }^{26}$ and the World Health Organization (WHO), ${ }^{27-29}$ have developed a number of population health frameworks and sets of measures.

In addition, the development and broad implementation of electronic health records $(\mathrm{EHRs})^{30}$ with ongoing data collection on large populations of patients and health information exchange (HIE) ${ }^{31}$ initiatives provide an unprecedented opportunity for public health professionals to assess the health of populations with real-time data and to move away from assessments based on limited surveys and medical claims data.

Considering the need for population health improvement in Maryland and elsewhere, and the collection of new data sources, it is important to develop a population health framework and set of relevant measurements that are usable at the state level. This manuscript presents the development of a population health framework as an evidence-based conceptual model for understanding population health at a state level, using Maryland as an example. It also identifies a preliminary set of population health measures derived from the framework and provides an assessment of various national and local data sources that could potentially be used to construct the proposed measures. Although this manuscript provides a comprehensive and evidence-based conceptual model for considering important factors for monitoring the health of the residents on a state or local level, in order to execute the proposed measures, states require the adoption of different methodologies, given their context and infrastructure. Maryland plans to directly integrate the set of proposed measures into the State's All-Payer Model Amendment. To align hospital and nonhospital provider incentives to encourage care redesign, population health also is featured in the Amendment. ${ }^{3}$

Although this project focuses on Maryland as an example and considers the public health priorities in Maryland in the process of developing the framework and proposing a set of population health measures, it could potentially guide health care and public health agencies across the nation to develop similar structures to address the population health needs of their respective communities.

\section{Methods}

To identify existing population health frameworks and measures, a comprehensive search of peer-reviewed and expert-authored literature was performed. In addition, an environmental scan was conducted of population health frameworks, including gray literature. Gray literature was included as recent population health initiatives are frequently published as guidelines and quality improvement reports. Also, major governmental and independent stakeholders in the field of population health provide reports and white papers that in essence define the field for their target audiences. ${ }^{32}$ The research team identified those articles and reports containing knowledge domains and topics that were deemed appropriate for inclusion in a population health framework as well as those that introduced specific population health measures.

In addition to a literature review, the research team scanned current population health and public health measures at Maryland Department of Health (MDH) and similar state and local public health agencies. The team identified population health frameworks and measures developed by the aforementioned major public health organizations including the CMS State Innovation Models ${ }^{19-24}$ and WHO country-level reports. ${ }^{27-29}$ The research team performed a semi-structured analysis to identify common themes and topics related to population health, and then developed a comprehensive list of available population health measures.

The research team organized the health system factors, determinants of health, and population-based as well as clinical outcomes identified in the literature review and environmental scan into an initial conceptual model of several domains and related subcategories (Fig. 1). The team then mapped all of the available population health measures into the conceptual model's domains and subcategories. The framework was expanded and modified based on feedback from an expert panel, consisting of representatives from $\mathrm{MDH}$ and health care leaders at the Johns Hopkins Health System - the largest health system in the state. The discussion was centered on the clarification of included domains, the organization of subcategories, and any gaps in the framework.

The research team developed a comprehensive list of criteria to select appropriate population health measures (Table 1). Using Maryland as the case study, the measures were narrowed through review cycles that allowed for local advice and expert panel input to develop refined selection criteria. At the end, 6 priority measures and 9 additional measures were identified based on the overall and customized criteria. Measurement specifications for the priority and additional measures were developed using a modified format outlined by NQF. ${ }^{33}$

In the next phase, an environmental scan was performed to find local, relevant data sources available in Maryland that could help construct the prioritized measures. For each major potential data source, the research team developed a matrix that outlined key characteristics, challenges, and opportunities as well as potential applicability to 1 or more of the 15 proposed population health measures. Furthermore, the team summarized the expected level of geographic details of the 

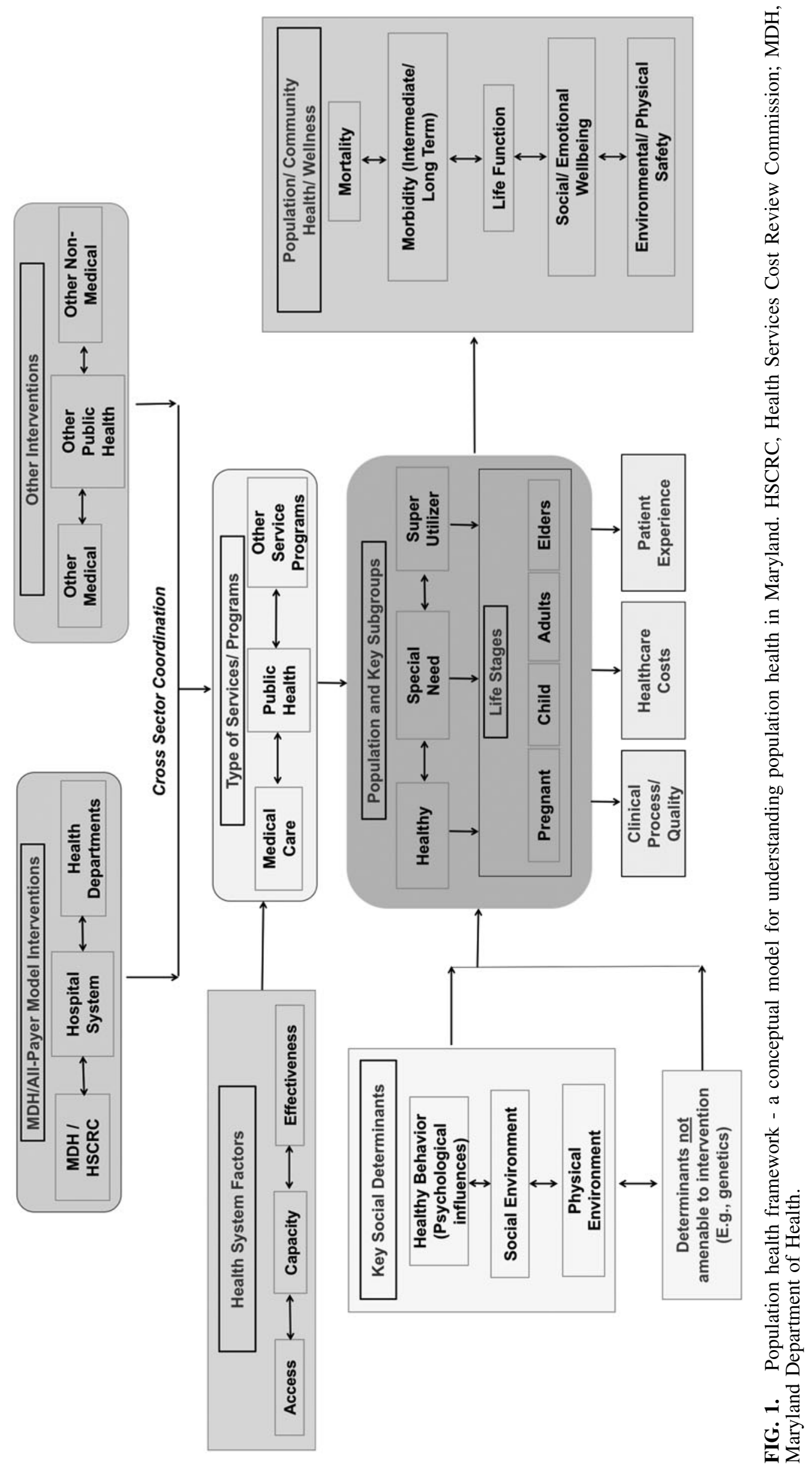

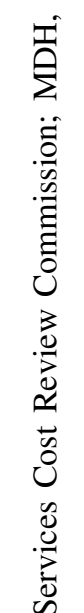


Table 1. Selection Criteria for Population Health Measures in Maryland

\begin{tabular}{|c|c|}
\hline Categories & Characteristics \\
\hline $\begin{array}{l}\text { Population/Community } \\
\text { Focused }\end{array}$ & $\begin{array}{l}\text { Relevant to community level interventions (eg, for entire state, county, or special } \\
\text { target population across region) } \\
\text { Health System Interventions (eg, a hospital system, ACO, or provider consortia) } \\
\text { Bringing population issues into clinical services (eg, PCP or care manager/outreach nurse) }\end{array}$ \\
\hline Importance/Applicability & $\begin{array}{l}\text { Population-based performance measures } \\
\text { Population-level factors that are important to take into account for clinical/public } \\
\text { health intervention }\end{array}$ \\
\hline $\begin{array}{l}\text { Development of a } \\
\text { Balanced Score Card } \\
\text { of Population Health }\end{array}$ & $\begin{array}{l}\text { Measures not related to medical care (ie, more social) } \\
\text { Focusing on population facets of medical care (ie, the full denominator of those } \\
\text { in need, not just those receiving care) } \\
\text { Focusing on interplay between public health interventions and medical care } \\
\text { A type of structure-oriented QI measure that will serve as a motivator to help build new } \\
\text { infrastructure for data collection for population health (eg, a metric assessing the } \\
\text { collection of SES data in EHRs) } \\
\text { Tools that will support not just the current state programs, but also future innovations } \\
\text { (eg, as described in the SIM grant) } \\
\text { Relevant to small areas (ie, when defining communities, one can go beyond just } \\
\text { county or large zip code) } \\
\text { Range of temporality (ie, some measures address short-term outcomes, others longer } \\
\text { term; some of the outcomes will require being in it for the long haul) }\end{array}$ \\
\hline $\begin{array}{l}\text { Overall Practicality and } \\
\text { Strategic Value }\end{array}$ & $\begin{array}{l}\text { Measurement areas not previously addressed by HSCRC/MDH or measures already } \\
\text { identified, but where further work is needed } \\
\text { Could be accomplished with limited resources (ie, not a new major community survey) } \\
\text { Fills a gap on the comprehensive framework developed }\end{array}$ \\
\hline $\begin{array}{l}\text { Data Feasibility/Supports } \\
\text { and Expands Digital } \\
\text { Infrastructure }\end{array}$ & $\begin{array}{l}\text { Data are currently available digitally or could be available in next } 3 \text { years } \\
\text { Capitalizes and expands on new data assets (eg, EHR, CRISP) }\end{array}$ \\
\hline $\begin{array}{l}\text { Scientific Evidence/ } \\
\text { Measures Attributes }\end{array}$ & $\begin{array}{l}\text { Some evidence that measures matter for health and welfare } \\
\text { Ideally some preliminary measurement work exists } \\
\text { Some previous validation of accuracy/feasibility desirable } \\
\text { Some previous measure standards/certification desirable }\end{array}$ \\
\hline
\end{tabular}

ACO, accountable care organization; CRISP, Chesapeake Regional Information System for Our Patients (Maryland); MDH, Maryland Department of Health; EHR, electronic health record; HSCRC, Health System Cost Review Committee (Maryland); PCP, primary care provider; QI, quality improvement; SES, socioeconomic status; SIM, State Innovation Model.

measures developed from the data sources to identify multiple ways to calculate the measures.

The final population health framework, list of proposed measures, and the potential data sources were presented to different stakeholders including The Maryland Association of County Health Officers ${ }^{34}$ (a private, nonprofit organization with the primary purpose of promoting the health and wellbeing of Maryland citizens), the MDH Dual Eligibles Care Delivery Workgroup ${ }^{6}$ (comprised of government officials, health care providers, payers, consumer advocates, community representatives, and other key stakeholders, led by the MDH and the Health Services Cost Review Commission), and the Reporting and Analytics Committee Meeting of the Chesapeake Regional Information System for Our Patients regional (CRISP ${ }^{35}$; a regional HIE serving Maryland and the District of Columbia). The final report also was available through MDH website for public review and comments. ${ }^{3}$

\section{Results}

\section{Developing the Maryland population health framework}

Several population health frameworks and categories of relevant measures were identified in the environmental search. The research team performed an analysis of those frameworks and measures, and reviewed $\mathrm{MDH}$-identified population health metrics. The team then developed a conceptual framework and process for developing a measure set for population health in Maryland (Fig. 1). This framework presents the multifaceted aspects of population health and interrelated sectors as well as the players in the field. This framework does not define the measures, but organizes the various ways in which community and population health can be measured, and illustrates how policy makers and other health care leaders might develop a targeted framework of measures.

The right side of the framework shows a way of conceptualizing broad population health outcomes and the left side represents the health system factors and key social determinants affecting the health of the population and key subgroups across life stages. The framework also presents major players in the health sector at a state level, and the type of services as well as the programs provided, including medical care, public health services, which potentially include community-level services and those services provided by the non-public health sector, such as the Department of Housing. Different components of the determinants and outcomes are arbitrarily sized and do not represent an equal impact on the health of the population, as are the domains 
within health system factors, clinical process, health care cost, and patient experience.

The research team divided the health system factors into 3 categories: (1) access, (2) capacity that addresses utilization of services, and (3) effectiveness, which addresses preventive services as well as screening programs. Health system factors would directly impact the services and programs provided by different sectors. Key social determinants included: (1) healthy behavior or psychosocial influences, which represents choices by individuals and communities and addresses lifestyle factors; (2) social environment, which represents a wide range of sociodemographic, socioeconomic, and socio-cognitive factors including education, income, occupation, health literacy, and attention to disparities; and (3) physical environment, which represents built infrastructure and natural resources.

The key social determinants affect subgroups of the population of healthy people, those with special needs, and super-utilizers across life stages from pregnancy to elderly. The research team divided the population health outcomes into mortality, morbidity, life function, social and emotional well-being, environment, and physical safety.

\section{Identifying potential Maryland population health measures and measurement specifications}

The research team began with a list of more than 80 potential population health measures for consideration. (The complete list of measures is available in Appendix 2 of the Maryland Population Health Measurement Development report.) $)^{3}$ The team mapped available population health measures into the developed framework and applied the comprehensive selection criteria presented in Table 1 to narrow down the list of the selected measures for Maryland through several review cycles. The team then provided detailed measurement specifications of the proposed priority measures with the intention to calculate each of the measures for various population denominators that are expanded beyond the traditional measure definition. Figure 2a presents the proposed population health measures in Maryland and Figure $2 \mathrm{~b}$ presents the measures' placement within the conceptual domains of the framework. The selected measures would serve as potential performance and community risk measures for various Maryland population-based statewide initiatives and reflect the public health priorities in Maryland; namely, reducing the burden of chronic illness, addressing health risk factors, nonmedical determinants of health, and improving health equity. In addition, CMS provided feedback on areas of focus as it related to the Maryland All-Payer Model.

The measurement specifications were drawn from existing population quality metrics for accountable providers such as accountable care organizations, health maintenance organizations, and patient-centered medical homes. These measures were then converted to cross-community (eg, geographic) measures to accommodate denominator definitions and data linkage. The proposed measures covered a broad set of populations health domains; the list included both process and outcome measures and reflected the available data sources while considering other selection criteria specified in Table 1. They also addressed the population health priorities in the short, mid, and long term.
Although some were existing measures in the current Maryland State Health Improvement Process (SHIP), ${ }^{36}$ most were derived from other measure sets to represent a balanced scorecard of population health for Maryland.

The measure specifications reflect the following considerations to develop population-level measures:

1. Residing in a specific geographic area (eg, a county or neighborhood)

2. Cared for or treated by a specific provider/health plan (eg, attribution would need to be defined such as majority of care from a health system, enrolled with a primary care provider, or covered by Medicaid)

3. Being a member of a certain subgroup (eg, selected age, sex, race cohorts)

\section{Assessing data sources for Maryland population health measures}

Various national and local data sources were assessed that could potentially be used to construct the 15 recommended measures. Table 2 presents the data sources (Table 2a) and the different levels of geographic detail of the measures available in each of the data sources (Table 2b). In selecting data sources, the research team considered their key characteristics, challenges, opportunities, and potential applicability to the recommended population health measures, as well as the issue of interoperability of data sources among different organizations.

\section{Discussion}

Total population- or community-wide interventions including interventions that are oriented to an entire population or subpopulation in a geographic area - are one of the CDC's 3 buckets of prevention. ${ }^{2}$ The other 2 include traditional clinical preventive interventions such as flu vaccine, colonoscopy, and screening for obesity or tobacco use, and innovative preventive interventions that extend care outside the clinical setting. An example would be detecting a disproportionate number of symptomatic asthmatic patients living in a specific area and designing home-based approaches to identify and reduce environmental triggers and to provide customized, home-based preventive educational counseling. $^{2}$

To achieve the population health goals, a systematic approach is required to quantify population health, assess its status and future progress, and to identify a scale for assessment in the form of population health measures. There are ongoing discussions about the application of relevant health-related quality measures and indices to assess the health of selected populations and to address the balance between improving health in a population versus reducing disparities across groups. ${ }^{7}$

These ongoing debates are reflected in the proposed framework and criteria to select population health measures. The focus of the proposed measures is on the population or community. ${ }^{2}$ The research team is aware that several of the proposed measures are similar to NQF measures ${ }^{15}$ or measures adopted from SHIP. ${ }^{36}$ These existing quality metrics were developed mainly for clinical providers such as accountable care organizations, health maintenance organizations, and patient-centered medical homes. To expand the 

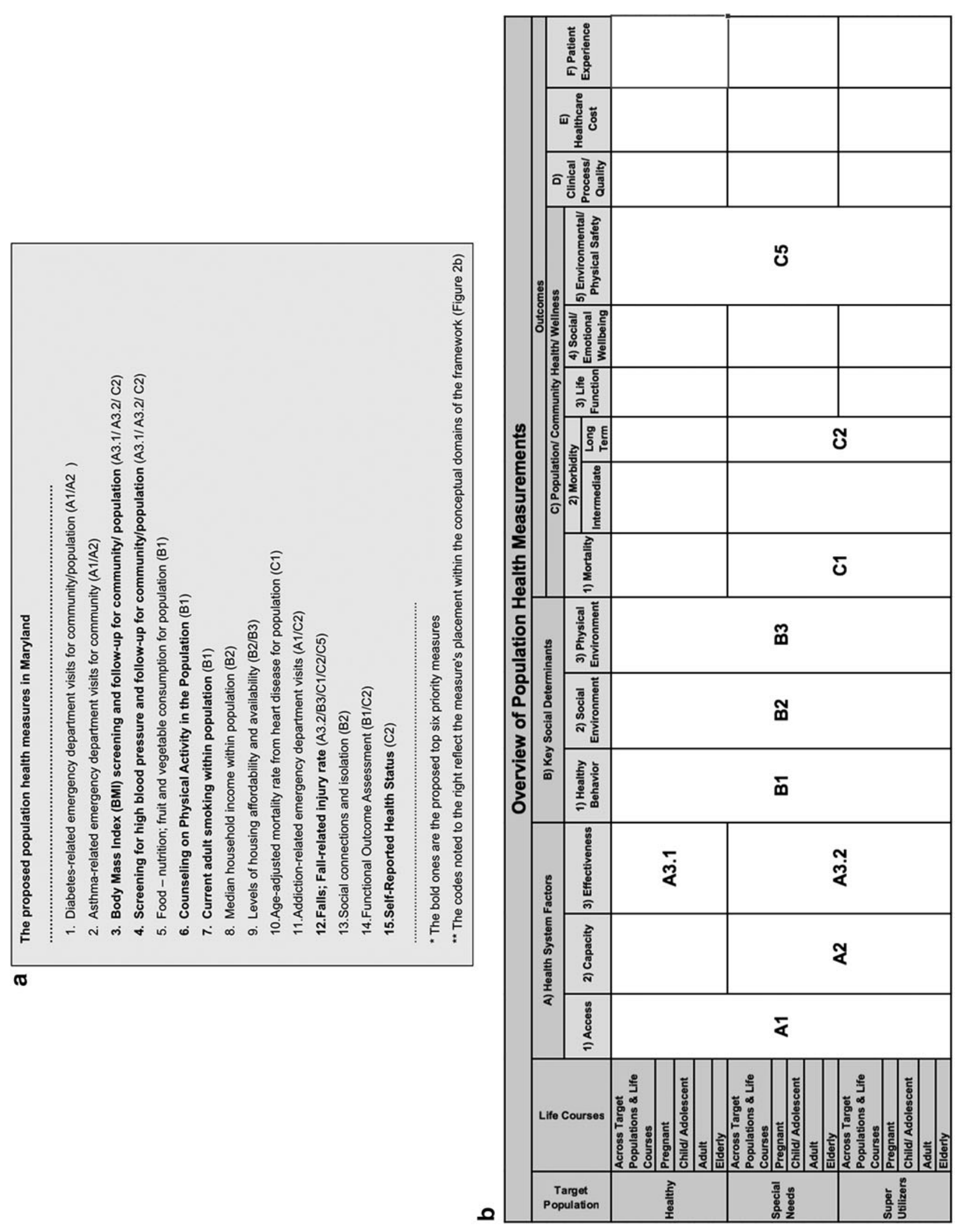

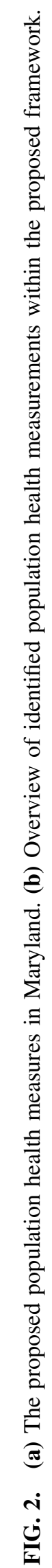


Table 2a. Summary of Data Sources Contributing to Recommended Population Health Measures

\begin{tabular}{|c|c|c|c|c|c|c|c|c|c|c|c|c|c|c|c|}
\hline \multirow[t]{2}{*}{ Summary of data sources } & \multicolumn{15}{|c|}{ Measures by number } \\
\hline & 1 & 2 & 3 & 4 & 5 & 6 & 7 & 8 & 9 & 10 & 11 & 12 & 13 & 14 & 15 \\
\hline Electronic health record & $\mathrm{X}$ & $\mathrm{X}$ & $\mathrm{X}$ & $\mathrm{X}$ & $\mathrm{x}$ & $\mathrm{X}$ & $\mathrm{x}$ & $\mathrm{X}$ & & $\mathrm{x}$ & $\mathrm{X}$ & $\mathrm{X}$ & $\mathrm{X}$ & $\mathrm{X}$ & $\mathrm{X}$ \\
\hline Health System Cost Review Committee (Maryland) & $\mathrm{X}$ & $\mathrm{x}$ & $\mathrm{X}$ & & & $\mathrm{X}$ & $\mathrm{x}$ & & & $\mathrm{x}$ & $\mathrm{X}$ & $\mathrm{x}$ & & & \\
\hline Maryland Health Care Commission & $\mathrm{X}$ & $\mathrm{x}$ & $\mathrm{X}$ & & & $\mathrm{X}$ & $\mathrm{x}$ & & & $\mathrm{x}$ & $\mathrm{X}$ & $\mathrm{x}$ & & & \\
\hline Behavioral Risk Factor Surveillance System & & & & & $\mathrm{x}$ & $\mathrm{X}$ & $\mathrm{x}$ & & & & & & $\mathrm{X}$ & & $\mathrm{x}$ \\
\hline $\begin{array}{l}\text { Chesapeake Regional Information System } \\
\text { for Our Patients }\end{array}$ & & $\mathrm{x}$ & & & & $\mathrm{x}$ & & & & & $\mathrm{x}$ & $\mathrm{x}$ & & & \\
\hline Census & & & & & $\mathrm{x}$ & & & $\mathrm{x}$ & $\mathrm{x}$ & & & & $\mathrm{x}$ & & $\mathrm{x}$ \\
\hline Vital Records & & & & & & & & & & $\mathrm{x}$ & & & & & \\
\hline Medicaid & $\mathrm{X}$ & $\mathrm{x}$ & & $\mathrm{X}$ & & $\mathrm{X}$ & & & & $\mathrm{x}$ & $\mathrm{X}$ & $\mathrm{x}$ & & & \\
\hline Maryland Department of Planning & & & & & & & & $\mathrm{X}$ & $\mathrm{x}$ & & & & & & \\
\hline Behavioral Health Administration & & & & & $\mathrm{x}$ & & & & & & & & $\mathrm{x}$ & $\mathrm{X}$ & $\mathrm{x}$ \\
\hline Youth Risk Behavior Surveillance System & & & & & $\mathrm{x}$ & $\mathrm{X}$ & & & & & & & & & \\
\hline Mobile Health Vans & & & $\mathrm{x}$ & $\mathrm{x}$ & & & $\mathrm{x}$ & & & & & & & & $\mathrm{x}$ \\
\hline School Health Clinics & & & $\mathrm{X}$ & $\mathrm{X}$ & $\mathrm{x}$ & $\mathrm{x}$ & & & & & & & $\mathrm{x}$ & $\mathrm{x}$ & $\mathrm{x}$ \\
\hline Community Health Fairs & & & $\mathrm{X}$ & $\mathrm{X}$ & $\mathrm{x}$ & $\mathrm{X}$ & & & $\mathrm{X}$ & & & & $\mathrm{X}$ & $\mathrm{x}$ & $\mathrm{x}$ \\
\hline Community Outreach & & & $\mathrm{x}$ & $\mathrm{x}$ & $\mathrm{x}$ & $\mathrm{x}$ & $\mathrm{x}$ & $\mathrm{x}$ & $\mathrm{x}$ & & & $\mathrm{x}$ & $\mathrm{x}$ & $\mathrm{X}$ & $\mathrm{x}$ \\
\hline Medicare Health Outcomes Survey & & & & & & $\mathrm{X}$ & & & & & & & & & \\
\hline
\end{tabular}

List of Measures: (1) Diabetes-related emergency department visits for community/population, (2) Asthma-related emergency department visits for community, (3) Body mass index screening and follow-up for community/population, (4) Screening for high blood pressure and follow-up for community/population, (5) Food - nutrition; fruit and vegetable consumption for population, (6) Counseling on physical activity in the population, (7) Current adult smoking within population, (8) Median household income within population, (9) Levels of housing affordability and availability, (10) Age-adjusted mortality rate from heart disease for population, (11) Addiction-related emergency department visits, (12) Falls; Fall-related injury rate, (13) Social connections and isolation, (14) Functional outcome assessment, (15) Self-reported health status.

current measures and convert them to cross-community measures, the denominator definitions and data linkage were expanded to address those in a specific geographic area or those with no connection to a health care system. The team considered the proposed measures as outcomes for which an organization might be held accountable (eg, the percentage of people in a catchment area who received a type of service). The measures also were defined to address the health equity and disparities in the populations, to provide better understanding of health care coverage across the state, and to identify communities with gaps in their provided health services.

Table 2B. The Expected Level of Available Geographic Details for Data Sources Contributing to Recommended Population Health Measures

\begin{tabular}{|c|c|c|c|c|}
\hline $\begin{array}{l}\text { Geographic } \\
\text { detail }\end{array}$ & Individual & $\begin{array}{l}\text { Zip codel } \\
\text { track }\end{array}$ & County & State \\
\hline Clinical & EHR & & & \\
\hline Administrative & CRISP & $\begin{array}{l}\text { HSCRC } \\
\text { MHCC/ } \\
\text { Claims }\end{array}$ & & Medicaid \\
\hline Survey & & $\begin{array}{l}\text { Census } \\
\text { MDP }\end{array}$ & BRFSS & $\begin{array}{l}\text { YRBSS } \\
\text { BHA }\end{array}$ \\
\hline Vital Records & & & $\begin{array}{l}\text { Birth } \\
\text { Death } \\
\text { Mortality }\end{array}$ & \\
\hline
\end{tabular}

BHA, Behavioral Health Administration; BRFSS, Behavioral Risk Factor Surveillance System; CRISP, Chesapeake Regional Information System for Our Patients (Maryland's Health Information Exchange); EHR, electronic health record; HSCRC, Health System Cost Review Committee (Maryland); MDP, Maryland Department of Planning; MHCC, Maryland Health Care Commission; YRBSS, Youth Risk Behavior Surveillance System.
In the proposed population health framework, the research team emphasized measures that had evidence of being amenable to change by health care or public health interventions, such as smoking level in a neighborhood. To move beyond hospital-oriented and clinical quality measures, new metrics ideally should address some of the population and community health or wellness domains in the proposed framework, with a goal of implementing the new measures that complement existing measures in the near future. In addition, the proposed measures were selected to support and expand the current digital infrastructure relevant to the studied state, Maryland, Census and other commonly collected geographic data, vital records and public health data available but not yet used, EHRs, and existing social/nonmedical data sources.

The ongoing expansion of EHRs in inpatient and outpatient settings could provide information not found in claims or administrative databases, which are typically used for measurement development. With the implementation of Medicare and Medicaid EHR Incentive Programs, ${ }^{37}$ the electronic capture of clinical data is becoming more standardized and data elements are being collected in a structured manner, allowing for continuous quality improvement at the point of care, easier data collection, and measurement. ${ }^{37}$ Standards such as Consolidated Clinical Document Architecture (CCDA) currently serve as the baseline standard for building electronic clinical documents. CMS is moving toward incorporating quality measurements in EHR reporting systems by introducing Quality Reporting Document Architecture (QRDA), a standard document format for the exchange of electronic clinical quality measure (eCQM) data. ${ }^{38}$

With continuous investment in population health data sources, the proposed measures could gradually move from health care-related measures with population health-oriented 
denominators to measures that address social determinants of health such as housing status, employment status, utilities, school system, or food deserts. This gradual shift will provide more in-depth assessment of factors playing a greater role in the health of populations, including those outside a particular health care system, and address heath equity and disparities. The shift also could relate to the application of population health measures in the public health surveillance services. For example, body mass index data collected in EHRs can be used as an indicator to establish an obesity surveillance system.

The application of nonclinical data in the development and execution of population health measures provides the platform for health systems and public health agencies to collaborate in the improvement of population health across the state. Population health is not confined to those receiving services in a health system nor is it achieved only by focusing on services through the health system. Population health requires an ongoing effort by all health sectors to address the clinical factors and social determinants of health. This provides an unprecedented opportunity for public health agencies at a local, state, and federal level and the private sector to reiterate their role in the health of communities and to apply their traditional public health skills in this new era of health reform. A good example would be the establishment of a patient-centered medical home model $^{5}$ with practice-based population health and proactive measurement as well as management of the panel of patients in an individual practice. ${ }^{39}$ Such an effort requires the management of factors affecting the health of patients, which are beyond the boundaries of a clinic and requires collaboration with public health professionals to address them.

There are a number of challenges to addressing the application of data sources in population health. A comprehensive data quality assessment of available data sources is required before operational rollout. A data quality check of these data sources also enables state and local health agencies to evaluate and improve the validity and reliability of the proposed population health measures. The actual level of geographic detail might vary for some aspects of each measure, and would be subject to verification during future stages of measure development and piloting. For example, data and measures that focus on a specific state or county are mostly aggregated and not detailed at a smaller geographic level, such as zip code or census tract. As the geographic resolution of such data sources becomes more granular, states would be able to develop a more detailed and accurate population for the proposed measures.

Alternatively, access to some metrics at finer levels of detail, such as individual address or census tract, would be subject to various privacy regulations and data governance provisions, and might need to be scaled up to large catchment areas. For example, hospital claims data, US Census data, and vital records are currently used for a multitude of measures; however, they provide only part of the larger picture.

Furthermore, exploring the availability of other data sources allows measures to be modified based on different population denominators for stakeholder needs. Putting more effort into developing ways to collect and use EHR data for population health measures and moving from a CCDA-based approach to QRDA data formats to capture the proposed measures should be a priority in the near future. Additional potential exists in the ability to collect additional information from clinical settings such as hospitals, ambu- lances, and primary care clinics. This will allow the proposed measures to be tested and validated against EHR/HIE data. Furthermore, HIEs and EHRs are available in most states, allowing the measures to be scaled up to other states if proven informative. ${ }^{40}$

Social, non-health-related, and nonclinical data require more in-depth assessment. There are a number of issues to address when it comes to application of non-health-related data. Data from these sources are not representative of larger populations, and it is unclear how complete and reliable these data sources are for the proposed measures. Data may not be linkable or may require a large effort to clean and make compatible. The data sources for selected metrics within a single organization need to be expanded across interoperable data sources.

The field of population health and available data sources to execute selected measurements are evolving rapidly. The suggested population health framework and set of measurements in this project act as a platform to quantify the overall goals in population health at the state level. The proposed framework enables the identification of specific underserved populations and the design of community-based interventions to address health disparities among them. The framework also provides guidance to evaluate and improve the quality of available data.

\section{Author Disclosure Statement}

The authors declared the following potential conflicts of interest: CMS State Innovation Model funds were used to facilitate this research. The Johns Hopkins University School of Public Health, Center for Population Health Information Technology (CPHIT) performed this research under contract to the Maryland Department of Health as a case study, which included data assessments and stakeholder input (the State included), as necessary. Any recommendations put forth in this manuscript are the views of the authors and do not necessarily represent the views of the Maryland Department of Health and Mental Hygiene.

\section{Prior Presentation}

A summary of the project and overall findings was presented at the "Panel on Preventive Medicine and Change facilitated by Clinical Informatics" during the annual meeting of the American College of Preventive Medicine, held May 23-26, 2017, in Portland, Oregon.

\section{References}

1. Berwick DM, Nolan TW, Whittington J. The triple aim: care, health, and cost. Health Aff (Millwood) 2008;27:759-769.

2. Auerbach J. The 3 buckets of prevention. J Public Health Manag Pract 2016;22:215-218.

3. Maryland Department of Health and Mental Hygiene. Health care transformation. 2016. https://Pophealth.health .maryland.gov/pages/transformation.aspx Accessed September 7, 2017.

4. Centers for Medicare \& Medicaid Services. Maryland AllPayer Model. https://Innovation.cms.gov/initiatives/marylandall-payer-model Accessed September 7, 2017.

5. Maryland Health Care Commission. Maryland Multi-Payer Patient Centered Medical Home Program. http://Mhcc .maryland.gov/pcmh Accessed September 7, 2017. 
6. Maryland Department of Health. Medicaid and Medicare Dual Eligibiles Care Delivery Strategy. Updated 2016. https://Mmcp.health.maryland.gov/sim/pages/home.aspx Accessed September 7, 2017.

7. Kindig DA. A pay-for-population health performance system. JAMA 2006;296:2611-2613.

8. Kharrazi H, Weiner JP. IT-enabled community health interventions: challenges, opportunities, and future directions. EGEMS (Wash DC) 2014;2:1117.

9. Institute of Medicine. Capturing Social and Behavioral Domains in Electronic Health Records; Phase 1. 2014. www .nationalacademies.org/hmd/reports/2014/capturing-socialand-behavioral-domains-in-electronic-health-records-phase1.aspx Accessed September 7, 2017.

10. Institute of Medicine. State of the USA Health Indicators: letter report. December 2008. https://www.nap.edu/read/12534/ chapter/2 Accessed September 7, 2017.

11. Institute of Medicine Report. Vital Signs: Core Metrics for Health and Health Care Progress. April 2015. http://Iom .nationalacademies.org/ /media/files/Report\%20Files/2015/ Vital_Signs/VitalSigns_RB.pdf Accessed September 7, 2017.

12. Alper J. Population Health Implications of the Affordable Care Act-Workshop Summary. www.nationalacademies .org/hmd/reports/2013/population-health-implications-of-theaffordable-care-act.aspx Accessed September 7, 2017.

13. Institute of Medicine. Toward Quality Measures for Population Health and the Leading Health Indicators. 2013. http:// Iom.nationalacademies.org/ /media/files/Report\%20Files/ 2013/quality-measures/QualityMeasuresRB.pdf Accessed September 7, 2017.

14. National Quality Forum Technical Report. Population health endorsement maintenance: Phase II technical report. Updated December 31, 2012. www.qualityforum.org/Projects/n-r/ Population_Health_Measures/Population_Health_Measures_ Endorsement_Maintenance_-_Phase_2.aspx Accessed September 7, 2017.

15. National Quality Forum. NQF-endorsed population health measures. March 13, 2014. www.qualityforum.org/QPS/ QPSTool.aspx?p=3863 Accessed September 7, 2017.

16. National Quality Forum. Multistakeholder input on a national priority: improving population health by working with communities-action guide 2.0. July 31, 2015. www .qualityforum.org/publications/2015/07/Population_Health_ Framework_-_Phase_2_-_Action_Guide_2_0.aspx Accessed September 7, 2017.

17. Jacobson DM, Teutsch S. An environmental scan of integrated approaches for defining and measuring total population health by the clinical care system, the government public health system, and stakeholder organizations. 2012. www.im provingpopulationhealth.org/PopHealthPhaseIICommissioned Paper.pdf Accessed September 7, 2017.

18. Stiefel M, Nolan K. A guide to measuring triple aim: population health, experience of care, per capita cost. IHI innovation series white paper. Cambridge, MA: Institute for Healthcare Improvement, 2012.

19. Centers for Medicare \& Medicaid Services; Center for Medicare \& Medicaid Innovation. Suggested population level measures for the CMS State Innovation Model Initiative. http://Innovation.cms.gov/files/x/SIMPopHlthMetrics .pdf Accessed September 7, 2017.

20. Washington State. 2014-2017 Creating a Culture of Health in Washington: State Health Improvement Plan. www.doh. wa.gov/portals/1/documents/pubs/822-034_SHIPreport.pdf Accessed September 7, 2017.
21. CMS Center for Medicare \& Medicaid Innovation. Model Test Application: New York State. Project Narrative. 2014; FON: CMS-1G1-14-001. www.health.ny.gov/technology/ innovation_plan_initiative/docs/ny_sim_project_narrative.pdf Accessed September 7, 2017.

22. State of California. California State Health Care Innovation Plan. March 31, 2014. www.chhs.ca.gov/InnovationPlan/ CalSIM\%20State\%20Health\%20Care\%20Innovation\%20 Plan_Final.pdf Accessed September 7, 2017.

23. Colorado Department of Public Health and Environment. Shaping a State of Health: Colorado's Plan for Improving Public Health and the Environment 2015-2019. https:// www.colorado.gov/pacific/sites/default/files/OPP_2015-COstate-plan.pdf Accessed September 7, 2017.

24. Vermont Health Care Innovation Project. Population health integration in the Vermont Health Care Innovation Project. http://Healthcareinnovation.vermont.gov/sites/hcinnovation/ files/Pop_Health/Pop\%20Health\%20in\%20VHCIP\%201112-14.pdf Accessed September 7, 2017.

25. Centers for Disease Control and Prevention. Community Health Assessment for Population Health Improvement: Resource of Most Frequently Recommended Health Outcomes and Determinants. 2013. https://wwwn.cdc.gov/Community Health/PDF/Final_CHAforPHI_508.pdf Accessed September 7, 2017.

26. Agency for Healthcare Research and Quality. The National Quality Measures Clearinghouse (NQMC) Domain Framework. www.qualitymeasures.ahrq.gov/about/domain-frame work.aspx Accessed September 7, 2017.

27. Solar O, Irwin A. A conceptual framework for action on the social determinants of health. social determinants of health discussion paper 2 (policy and practice). 2010. www.who.int/ sdhconference/resources/Conceptualframeworkforactionon SDH_eng.pdf Accessed September 7, 2017.

28. Canadian Institute for Health Information. The Canadian National Consensus Conference on Population Health Indicators. 1994. https://Secure.cihi.ca/free_products/phi.pdf Accessed September 7, 2017.

29. Department of Health. The Public Health Outcomes Framework for England, 2013-2016. 2012. https://www.gov .uk/government/uploads/system/uploads/attachment_data/ file/216159/dh_132362.pdf Accessed September 7, 2017.

30. Office of the National Coordinator for Health Information Technology. Adoption of Electronic Health Record Systems among U.S. Non-Federal Acute Care Hospitals: 20082015. Updated May 2016. https://Dashboard.healthit.gov/ evaluations/data-briefs/non-federal-acute-care-hospital-ehradoption-2008-2015.php Accessed September 7, 2017.

31. Office of the National Coordinator for Health Information Technology. Connecting Health and Care for the Nation: A 10-year Vision to Achieve an Interoperable Health IT Infrastructure. Updated June 2014. https://www.healthit.gov/ sites/default/files/ONC10yearInteroperabilityConceptPaper .pdf. Accessed September 7, 2017.

32. Harris D, Puskarz K, Golab C. Population health: curriculum framework for an emerging discipline. Popul Health Manag 2016;19:39-45.

33. National Quality Forum. The consensus standards approval committee on quality performance measure construction. https:// www.qualityforum.org/WorkArea/linkit.aspx?LinkIdentifier= id\&ItemID=689992011 Accessed September 7, 2017.

34. The Maryland Association of County Health Officers. www .mdcounties.org/index.aspx?nid=120 Accessed September 7, 2017. 
35. Chesapeake Regional Information System for Our Patients. https://Crisphealth.org Accessed September 7, 2017.

36. Maryland Department of Health and Mental Hygiene. Maryland State Health Improvement Process. 2015. http:// Dhmh.maryland.gov/ship/pages/home.aspx Accessed September 7, 2017.

37. Center for Medicare and Medicaid Services: Electronic Health Records (EHR) Incentive Programs. Updated 2016. https://www.cms.gov/regulations-and-guidance/legislation/ EHRIncentivePrograms/index.html?redirect=/ehrincentive programs Accessed September 7, 2017.

38. Centers for Medicare and Medicaid Services; Office of the National Coordinator for Health Information Technology. What is the quality reporting document architecture (QRDA)? Updated 2016. https://Ecqi.healthit.gov/qrda Accessed September 7, 2017.

39. Cusack CM, Knudson AD, Kronstadt JL, Singer RF, Brown AL. Practice-based population health: information technology to support transformation to proactive primary care. AHRQ Publication No. 10-0092-EF. Rockville, MD: Agency for Healthcare Research and Quality, 2010.

40. Kharazi H, Horrocks D, Weiner J. Use of HIEs for valuebased care delivery: a case study of Maryland's HIE. In: Dixon BE, ed. Health information exchange: navigating and managing a network of health information system. Oxford, United Kingdom: Elsevier Inc., 2016:313-332.

Address correspondence to: Elham Hatef, $M D, M P H$ Center for Population Health IT Department of Health Policy and Management Johns Hopkins Bloomberg School of Public Health 624 North Broadway, Room 501 Baltimore, MD 21205

E-mail: ehatef1@jhu.edu 